УДК 538.9:536.6

\title{
ТЕПЛОФИЗИЧЕСКИЕ ХАРАКТЕРИСТИКИ ВЫСОКОТЕПЛОПРОВОДНЫХ ПОЛИМЕРНЫХ МИКРО- И НАНОКОМПОЗИТОВ
}

Долинский А.А. ${ }^{1}$, академик НАН Украины, Фиалко Н.М. ${ }^{1}$, член-корреспондент НАН Украины, Динжос P.B. ${ }^{2}$, канд. физ.-мат. наук, Навродская Р.А. ${ }^{1}$, канд. техн. наук

${ }^{1}$ Институт технической теплофизики НАН Украины, ул. Желябова, 2 а, Киев, 03680, Украина

${ }^{2}$ Николаевский национальный университет им. В.А.Сухомлинского, ул. Никольская, 24, Николаев, 54030, Украина

\begin{abstract}
Наведено результати досліджень 3 розробки типоряду високотеплопровідних полімерних мікро- і нанокомпозитів на основі частково кристалічних та аморфних полімерів для виготовлення теплообмінних поверхонь. Представлено дані експериментів 3 визначення таких характеристик композиційних матеріалів цього типоряду, як коефіцієнт теплопровідності, питома теплоємність та максимальна температура експлуатації.
\end{abstract}

Приведены результаты исследований по разработке типоряда высокотеплопроводных полимерных микро- и нанокомпозитов на основе частично кристаллических и аморфных полимеров для изготовления теплообменных поверхностей. Представлены данные экспериментов по определению таких характеристик композиционных материалов этого типоряда, как коэффициент теплопроводности, удельная теплоемкость и максимальная температура эксплуатации.
The results of research to develop of the type series of the high-heat transfer polymer micro- and nanocomposites based on partially crystalline and amorphous polymers for the manufacture of heat exchange surfaces are presented. The data of experiments to determine such characteristics of the composite materials of this series as thermal conductivity, specific heat and maximum operating temperature are given.

Библ. 10, рис. 3, табл. 4.

Ключевые слова: полимерные микро- и нанокомпозиты, теплообменные поверхности, тепломфизические свойства.

$c_{p}$ - удельная массовая теплоемкость, кДж/(кг·К);

$T$ - температура, К;

$T_{\max }^{\text {эк }}$ - максимальная температура эксплуатации композита, К;

$T_{\text {пл, }}, T_{\text {ст }}$ - температура плавления и стеклования, К;

$\lambda$ - коэффициент теплопроводности, Вт/(м·К);

$\chi$ - степень кристалличности, $\%$;

\section{Введение}

Перспективность использования полимерных микро- и нанокомпозитов для создания теплообменных поверхностей различного назначения связана с комплексом их характеристик, таких как необходимые теплофизические свойства, высокая коррозионная стойкость, относительно небольшой удельный вес и пр. [1-7].

При разработке данных композитов и анализе их теплофизической эффективности в первую очередь следует принимать во внимание предъ- $\omega$ - массовая доля наполнителя, \%;

\section{Сокращения:}

ПК - поликарбонат;

ПММА - полиметилметакрылат;

ПП - полипропилен;

ПЭ - полиэтилен;

УНТ - углеродные нанотрубки.

являемые к ним требования в части теплопроводящих свойств и допустимых уровней рабочих температур. И поскольку для теплообменников разного типа отмеченные требования могут весьма существенно отличаться, то актуальной является задача создания соответствующего ряда модификаций полимерных композитов.

В настоящей статье рассматриваются основные аспекты разработки микро- и нанокомпозиционных полимерных материалов для изготовления теплообменных поверхностей с различным 
диапазоном температур эксплуатации и разными теплопроводящими свойствами материала их стенок.

\section{Постановка задачи и методика проведения исследований}

В работе ставилась задача разработки типо- ряда полимерных микро- и нанокомпозитов с коэффициентом теплопроводности, изменяющимся от 20 до 60 Вт/(м·К), и максимальной температурой эксплуатации, находящейся в пределах $390 \ldots 470$ К. В табл. 1 приведены основные характеристики и обозначения материалов данного типоряда.

Таблица 1. Основные характеристики и обозначения разрабатываемого типоряда полимерных композиционных материалов для теплообменных поверхностей

\begin{tabular}{|c|c|c|c|}
\hline \multirow{2}{*}{$\lambda, \mathrm{BT} /(\mathbf{M} \cdot \mathrm{K})$} & \multicolumn{3}{|c|}{ Обозначения элементов типоряда материалов } \\
\cline { 2 - 4 } & \multicolumn{3}{|c|}{ Максимальная температура эксплуатации материала, $\mathrm{K}$} \\
\cline { 2 - 4 } & 390 & 425 & 470 \\
\hline 20 & $\mathrm{~A} 1$ & $\mathrm{~B} 1$ & $\mathrm{C} 1$ \\
\hline 25 & $\mathrm{~A} 2$ & $\mathrm{~B} 2$ & $\mathrm{C} 2$ \\
\hline 30 & $\mathrm{~A} 3$ & $\mathrm{~B} 3$ & $\mathrm{C} 3$ \\
\hline 35 & $\mathrm{~A} 4$ & $\mathrm{~B} 4$ & $\mathrm{C} 4$ \\
\hline 40 & $\mathrm{~A} 5$ & $\mathrm{~B} 5$ & $\mathrm{C} 5$ \\
\hline 45 & $\mathrm{~A} 6$ & $\mathrm{~B} 6$ & $\mathrm{C} 6$ \\
\hline 50 & $\mathrm{~A} 7$ & $\mathrm{~B} 7$ & $\mathrm{C} 7$ \\
\hline 55 & $\mathrm{~A} 8$ & $\mathrm{~B} 8$ & $\mathrm{C} 8$ \\
\hline 60 & $\mathrm{~A} 9$ & $\mathrm{~B} 9$ & $\mathrm{C}$ \\
\hline
\end{tabular}

Возможности разработки указанного типоряда материалов рассматривались с использованием в качестве полимерных матриц частично кристаллических полимеров - полиэтилена, полипропилена и поликарбоната, и аморфного полимера - полиметилметакрылата. При этом в качестве наполнителей применялись УНТ, а также микрочастицы меди и алюминия. Содержание наполнителей варьировалось от 0,2 до $10 \%$. Методы получения наполнителей - УНТ и микрочастиц алюминия, а также их характеристики описаны в [8]. Что же касается микрочастиц меди, то они готовились таким же образом, как и частицы алюминия. Для получения композитов использовался метод, основанный на смешивании компонентов в расплаве полимера [9].

В задачу работы входило проведение экспериментальных исследований величин коэффициента теплопроводности и удельной теплоемкости композитов, составленных из рассматриваемых полимерных матриц и наполнителей в заданном диапазоне изменений доли наполнителей. Мето- дики определения указанных теплофизических свойств приведены в [8].

На основе полученных температурных зависимостей теплоемкости находились значения температур плавления для композитов с частично кристаллической матрицей и температур стеклования для композитов с аморфной матрицей. Соответствующие максимальные температуры эксплуатации композитов определялись из условия, согласно которому температура плавления (стеклования) должна превышать данную температуру примерно на 20 К [10].

Полученные экспериментальные данные о зависимостях $\lambda=f(\omega)$ для исследуемых полимерных композитов, а также данные о максимальных значениях температур их эксплуатации служили основой для определения разрабатываемого типоряда материалов. Далее из множества композитов, отвечающих некоторому элементу данного типоряда, выбирался один из соображений наименьшей стоимости составляющих его компонентов. 


\section{Результаты исследований и их анализ}

Рассмотрим вначале данные экспериментальных исследований зависимости от температуры удельной теплоемкости получаемых полимерных композитов. На рис. 1 представлены характерные результаты этих исследований для композитов на основе частично кристаллических полимеров (ПЭ, ПП, ПК), на рис. 2 - для композитов на
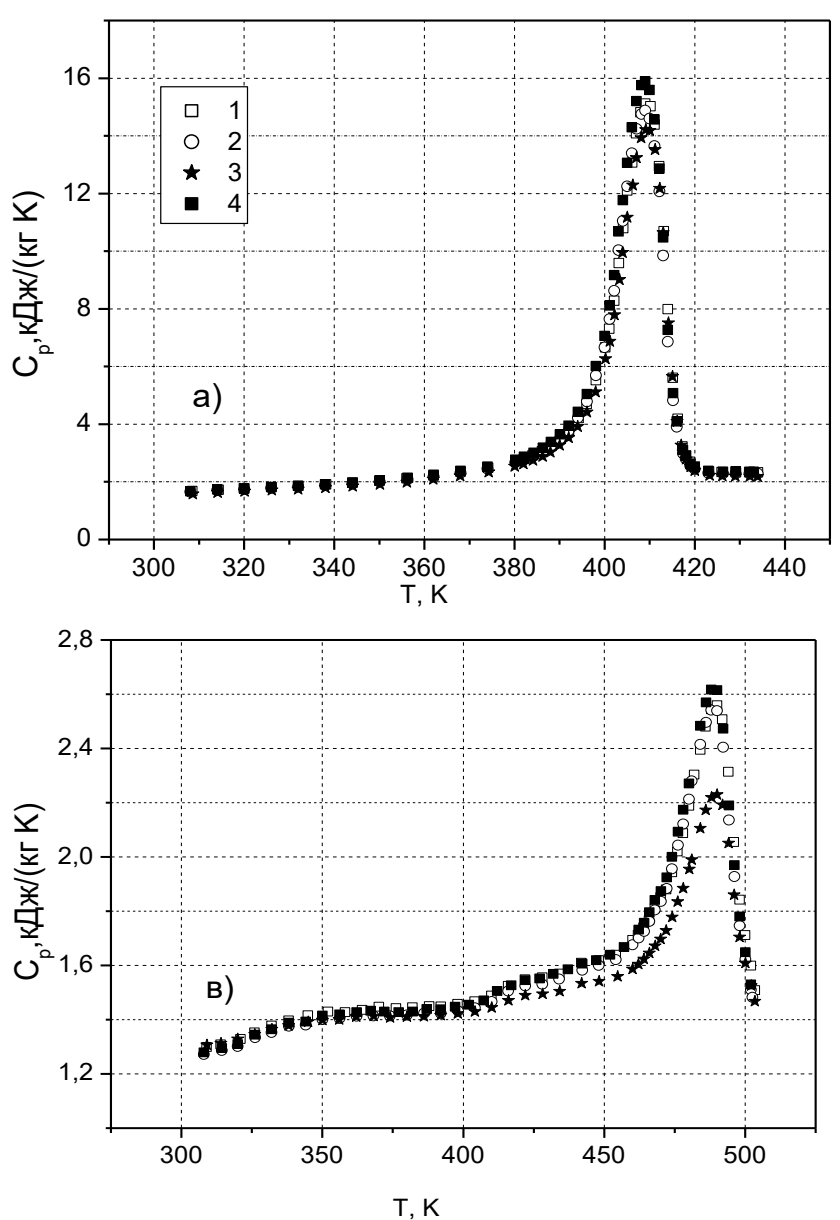

Как видно из рис. 1, теплоемкость композитов на основе всех рассматриваемых полимерных матриц в области ее наибольших значений, отвечающих интервалу температур плавления, оказывается несколько ниже, чем теплоемкость соответствующих матриц. Указанное понижение для композитов на основе одной и той же полимерной матрицы является максимальным по величине при использовании в качестве наполнителя углеродных нанотрубок, несколько меньшим - микрочастиц меди, и наименьшим - основе аморфного полимера ПММА. Приведенные данные отвечают максимальному из рассмотренных значений содержания микро- и нанонаполнителей $(\omega=10 \%)$, при котором, как показали выполненные эксперименты, имеют место наибольшие отклонения величин теплоемкости от ее значений для ненаполненного полимера.

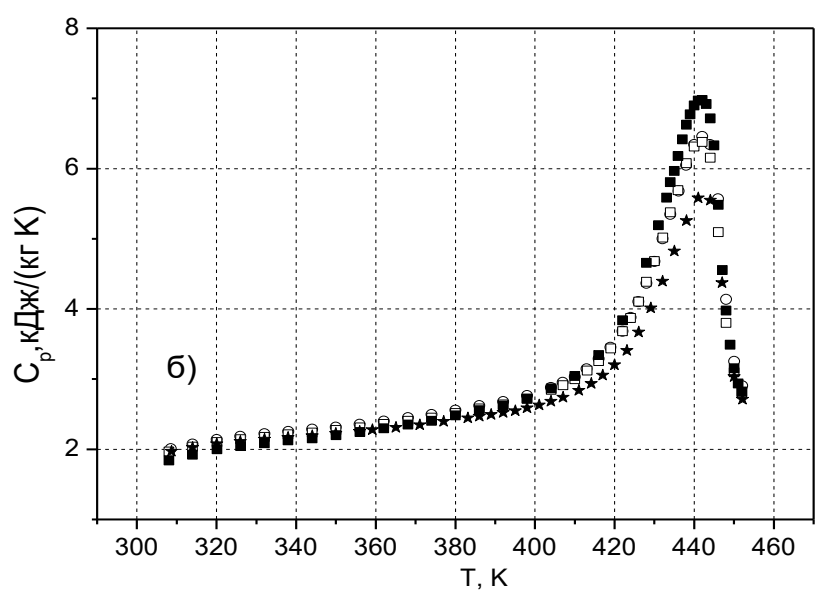

Рис. 1. Зависимость от температуры удельной теплоемкости композитов на основе частично кристаллических полимеров - полиэтилена (а), полипропилена (б), и поликарбоната (в) при использовании различных наполнителей для $\omega=10 \%$ : 1 - Al; 2 - Си; 3 - УНT;

обозначение 4 отвечает соответствующим полимерным матрицам.

микрочастиц алюминия.

На основе полученных зависимостей $c_{p}=f(T)$ могут быть определены значения степени кристалличности разработанных композитов по соотношению, приведенному в [10]. Соответствующие результаты расчетов представлены в табл. 2.

Согласно приведенным в таблице данным степень кристалличности полимерных матриц превышает ее значения для композиционных материалов на основе этой матрицы. Причем величина указанного превышения зависит от 
типа используемого наполнителя. А именно, наибольшее превышение отвечает углеродным нанотрубкам, наименьшее - алюминию. Описанная картина изменения степени кристалличности композитов отвечает, как будет показано ниже, определенным закономерностям поведения коэффициентов теплопроводности данных материалов.

Характер температурной зависимости $c_{p}$ для композитов на основе аморфного полимера существенно отличается от такового для частично кристаллических полимеров (сопоставьте данные на рис. 1 и 2). Как видно, теплоемкость композитов на основе аморфных полимеров повышается с ростом температуры, зависимость же от температуры теплоемкости композитов на основе частично кристаллических полимеров носит экстремальный характер.

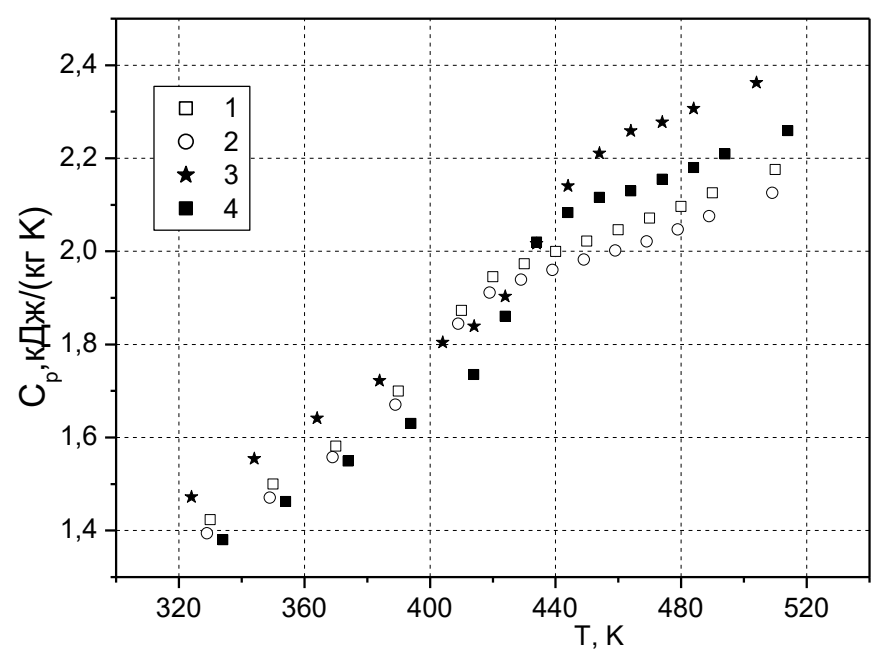

Рис. 2. Зависимость от температуры удельной теплоемкости композитов на основе полиметилметакрылата при использовании различных наполнителей для $\omega=10 \%: 1-A l ; 2-C и ; 3-У Н T$; обозначение 4 отвечает полимерной матрице.

Таблица 2. Значения степени кристалличности полимерных матриц $\chi_{\text {}}$, композитов $\chi_{\kappa}$ и величины их отличий $\Delta \chi\left(\Delta \chi=\chi_{\mathrm{м}}-\chi_{\mathrm{K}}\right)$ при $\omega=10 \%$

\begin{tabular}{|c|c|c|c|c|}
\hline $\begin{array}{c}\text { Тип } \\
\text { полимерной } \\
\text { матрицы }\end{array}$ & $\begin{array}{c}\text { Степень } \\
\text { кристалличности } \\
\text { матрицы } \chi_{\text {, }} \%\end{array}$ & $\begin{array}{c}\text { Тип } \\
\text { наполнителя }\end{array}$ & $\begin{array}{c}\text { Степень } \\
\text { кристалличности } \\
\text { композита } \chi_{k}, \%\end{array}$ & $\begin{array}{c}\text { Отличие степени } \\
\text { кристалличности } \\
\Delta \chi, \%\end{array}$ \\
\hline \multirow{3}{*}{ ПЭ } & \multirow{3}{*}{76,0} & $\mathrm{Al}$ & 71,3 & 4,7 \\
\hline & & $\mathrm{Cu}$ & 69,4 & 6,6 \\
\hline & & УHT & 63,8 & 12,2 \\
\hline \multirow{3}{*}{$\Pi \Pi$} & \multirow{3}{*}{51,0} & Al & 46,8 & 4,2 \\
\hline & & $\mathrm{Cu}$ & 43,8 & 7,2 \\
\hline & & УHT & 31,3 & 19,7 \\
\hline \multirow{3}{*}{ ПК } & \multirow{3}{*}{24,0} & $\mathrm{Al}$ & 23,7 & 0,3 \\
\hline & & $\mathrm{Cu}$ & 23,4 & 0,6 \\
\hline & & УНТ & 21,5 & 2,5 \\
\hline
\end{tabular}


Как видно из рис. 2, величина $c_{p}$ для наполненных аморфных полимеров в диапазоне температур от температуры окружающей среды до температуры стеклования композита изменяется практически линейно. При этом теплоемкость ненаполненного полимера во всем указанном диапазоне оказывается более низкой, чем композитов. Что же касается последних, то их теплоемкость по мере убывания ранжируется следующим образом: композиты, наполненные углеродными нанотрубками, микрочастицами меди и алюминия. Следует отметить, что таким же образом ранжируются и теплоемкости указанных наполнителей.

Согласно полученным данным, при приближении к температуре стеклования теплоемкость как наполненных, так и ненаполненных аморфных полимеров весьма резко возрастает. Величина данного возрастания $\Delta c_{p}$ определяет, как известно, энергию активации, необходимую для перехода из стеклообразного состояния в вязкотекучее. Как видно из рис. 2 , значение $\Delta c_{p}$ является наибольшим для полимеров, наполненных УНТ, и существенно меньше для полимеров, наполненных микрочастицами меди алюминия. Так, $\Delta c_{p}=0,30 ; 0,18$ и 0,14 кДж/(кг·К) при наполнении полиметилметакрылата УНТ, Cu и Al.

Приведенные на рис. 1 и 2 зависимости $c_{p}=f(T)$ позволяют определить максимальные температуры их эксплуатации. Как свидетельствуют полученные данные (рис. 1), температуры плавления рассмотренных композитов на основе частично кристаллических полимеров практически совпадают с температурами плавления соответствующих ненаполненных полимеров. То есть температуры плавления композитов на основе полиэтилена равны 410 К, на основе полипропилена 445 К и на основе поликарбоната 490 К. Соответствующие максимальные температуры эксплуатации, найденные из указанного выше условия $T_{\max }^{\text {эк }}=T_{\text {пл }}-20 \mathrm{~K}$, составляют 390,425 , $470 \mathrm{~K}$.

Несколько иная картина наблюдается для разрабатываемых композитов на основе аморфного полимера ПММА. Здесь температуры стеклования для композитов и ненаполненного полимера не совпадают. При этом эти температуры для композитов в зависимости от типа наполни- теля могут быть как больше, так и меньше температуры стеклования ненаполненного полимера. Так, для полимеров, наполненных УНТ, температура стеклования превышает ее значение для полимерной матрицы. (При $\omega=10 \%$ температура $T_{\text {ст }}$ для композитов с УНТ составляет $435 \mathrm{~K}$, а для матрицы - 424 К). Для полимеров, наполненных $\mathrm{Cu}$ и $\mathrm{Al}$, температура стеклования оказывается ниже, чем для полимерной матрицы. (При $\omega=10 \%$ величина $T_{\text {ст }}$ для этих композитов равняется примерно 410 К). Если принять для рассматриваемого типа композитов в качестве температуры стеклования наименьшую из указанных выше температур ( $\left.T_{\text {ст }} \approx 410 \mathrm{~K}\right)$, то максимальная температура эксплуатации составит 390 К. То есть рассматриваемые композиты на основе аморфного полимера ПММА могут быть отнесены к материалам типа А (см. табл. 1).

Перейдем далее к анализу результатов экспериментальных исследований по определению величины коэффициента теплопроводности разрабатываемых полимерных композитов. Данные на рис. 3 иллюстрируют зависимости значений коэффициента теплопроводности композитов от массовой доли рассматриваемых наполнителей $\omega$ для всех используемых в рамках настоящей работы полимерных матриц. Согласно результатам проведенных исследований при увеличении содержания наполнителей имеет место повышение значений $\lambda$. Причем это повышение при некоторых содержаниях наполнителя, называемых порогами перколяции, является достаточно резко выраженным. В рассматриваемых условиях значения первого порога перколяции, отвечающего образованию из частичек наполнителя непрерывного перколяционного кластера, находится в диапазоне $\omega=0,5 \ldots 0,8 \%$, а второго порога перколяции, соответствующего формированию перколяционной сетки, - в диапазоне $\omega=1,8 \ldots 2,5 \%$.

Как видно из рис. 3, разрабатываемые композиты характеризуются весьма широкими пределами изменения коэффициента теплопроводности. При этом максимально достижимые уровни $\lambda$ композитов являются существенно различными для разных наполнителей. Так, для $\omega=10 \%$ величины коэффициентов теплопроводности 
композитов могут достигать 60,$9 ; 41,5$ и $28,9 \mathrm{BT} /(м \cdot К)$ при использовании в качестве наполнителей УНТ, $\mathrm{Cu}$ и $\mathrm{Al}$ соответственно.

Что же касается полимерных матриц, то, как свидетельствуют полученные данные, каждому типу наполнителя отвечает определенная матрица, при использовании которой коэффициент теплопроводности композита для фиксированного значения содержания наполнителя является наибольшим. Так, в диапазоне изменения $\lambda=20 \ldots 60 \mathrm{BT} /(\mathrm{M} \cdot \mathrm{K})$ указанное наибольшее значение $\lambda$ для УНТ имеет место при использовании в качестве полимерной матрицы ПММА, а для $\mathrm{Cu}$ и $\mathrm{Al}$ - матрицы из ПП. С другой стороны, каждому типу наполнителя соответствует полимерная матрица, в случае применения которой $\lambda$ композита оказывается наименьшим при заданной величине $\omega$. Для рассматриваемого диапазона изменения коэффициента теплопроводности композита
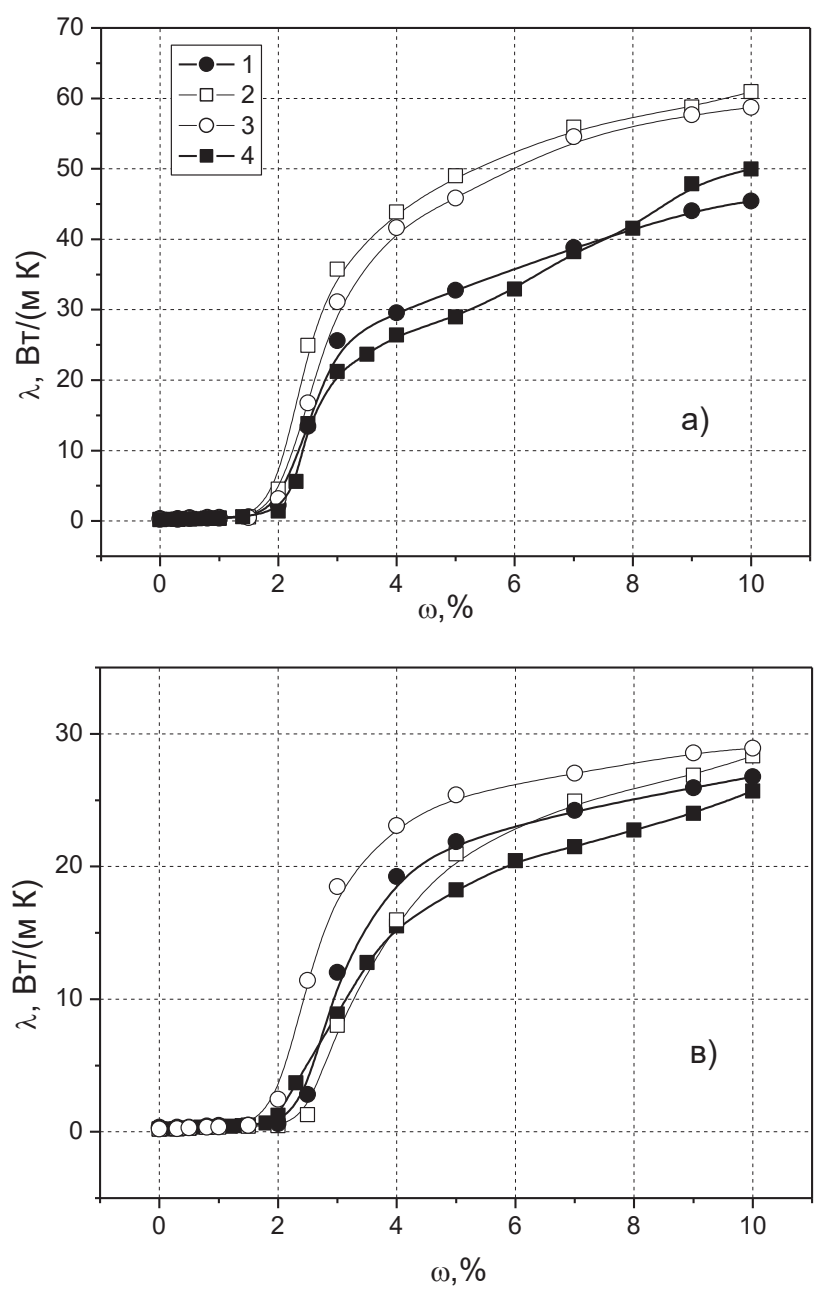

его наименьшее значение наблюдается для УНТ при использовании матрицы из полиэтилена или поликарбоната в зависимости от величины $\omega$, для $\mathrm{Cu}$ - матрицы из полиэтилена и для $\mathrm{Al}$ - матрицы из поликарбоната.

Согласно результатам выполненных исследований при использовании частично кристаллических матриц изменение степени их кристалличности, наблюдаемое в процессе получения композиционного материала, коррелируется определенным образом с уровнем теплопроводящих свойств данного материала. Как уже отмечалось, степень кристалличности композита для всех рассмотренных ситуаций оказывается меньше ее величины для соответствующего ненаполненного полимера. Действительно, ввиду образования в композите разветвленных перколяционных структур степень кристалличности полимерной матрицы уменьшается. При

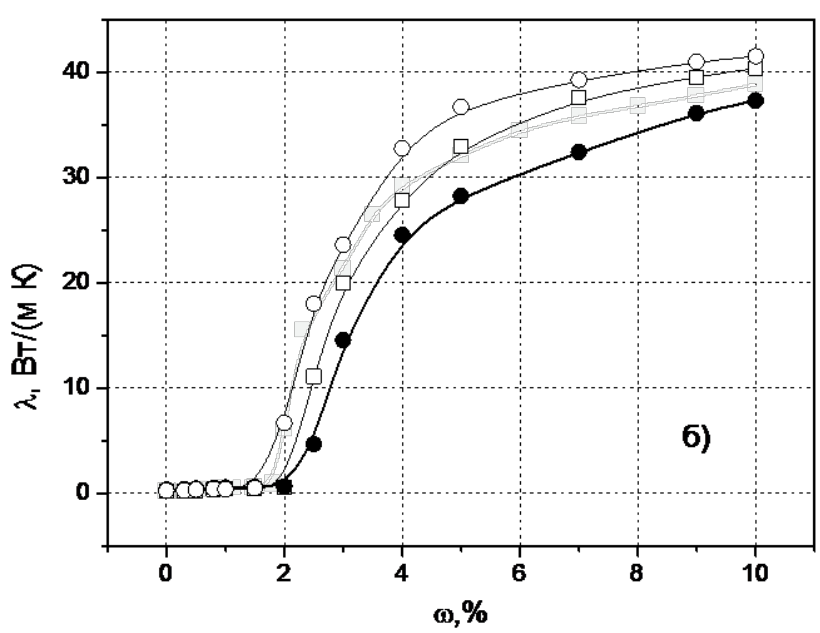

Рис. 3. Зависимость коэффициента теплопроводности полимерных композиционных материалов от массовой доли наполнителя при использовании в качестве полимерных матриц полиэтилена (1), полиметилметакрылата (2), полипропилена (3) и поликарбоната (4) для различных типов наполнителя: a) $У Н T$; б) $\mathrm{Cu}$; в) $\mathrm{Al}$. 
этом чем более разветвленными являются данные структуры, тем значительнее снижается указанная степень кристалличности. В плане же величин коэффициентов теплопроводности композитов развитие проводящих перколяционных структур обуславливает повышение теплопроводящих свойств композиционных материалов. Таким образом, большим отличиям степени кристалличности ненаполненных полимеров и соответствующих композитов должны отвечать более высокие значения коэффициентов теплопроводности композитов. Полученные экспериментальные данные подтверждают справедливость приведенных соображений. Например, при использовании полипропилена указанные отличия степени кристалличности составляют для наполнителей из $\mathrm{Al}, \mathrm{Cu}$ и УНТ 4,2; 7,2 и 19,7 \% (табл. 2). Соответствующие же значения коэффициентов теплопроводности композитов равны 28,$9 ; 41,5$ и $58,7 \mathrm{BT} /(\mathrm{M} \cdot \mathrm{K})$.

На основе результатов выполненных исследований коэффициентов теплопроводности полимерных композитов были определены их составы, при которых начения $\lambda$ равны соответствующим заданным величинам для разрабатываемого типоряда материалов (см. табл. 3). С использованием данных, приведенных в табл. 3, и результатов экспериментов по нахождению максимальных температур эксплуатации разрабатываемых композитов были установлены их составы для каждого из элементов указанного типоряда. При этом принималось во внимание следующее. Полагалось, что в каждую из рассматриваемых групп композитов А, В и С включаются композиты, максимальная температура которых превышает некоторую заданную для данной группы величину $T_{\max }^{\text {жк }}$. Соответственно этому, группу А составляли все рассматриваемые композиты, группу В - композиты на основе полипропилена и поликарбоната, а группу C композиты на основе поликарбоната.

Согласно полученным данным каждому элементу разрабатываемого типоряда может отвечать множество композитов. Так, элементу A1 соответствует 12 композитов, элементу В1 - 6, элементу C1 - 3. Из каждого множества композитов был выбран один по соображениям минимальной общей стоимости его компонентов (см. табл. 4). При расчетах указанные стоимости принимались по данным Лондонской товарной биржи, осредненным за период с сентября 2014 г. по август 2015 г., и составляли за тонну материала: для полиэтилена - 268\$, полиметилметакрылата - 305\$, полипропилена - 315 \$, поликарбоната $-390 \$$, УНТ $-3350 \$, \mathrm{Cu}-5800 \$$ и $\mathrm{Al}-2030 \$$.

Как видно из табл. 4, стоимость материалов для композитов группы В весьма незначительно превышает стоимость материалов для соответствующих элементов группы А. Это связано с тем, что стоимость полипропилена, являющегося матрицей для всех композитов группы В, не намного превышает стоимость матрицы из полиметилметакрылата, на основе которой сформировано большинство композитов группы А. Кроме того наблюдаемая тенденция к повышению доли наполнителя для материалов группы В по сравнению с группой А является весьма слабо выраженной. То есть доля стоимости наполнителей в общей стоимости композита повышается для материалов группы В незначительно.

Что же касается соотношения стоимостей материалов для композитов групп В и С, то имеют место ее существенно большие значения для материалов группы С. Последнее обусловлено, с одной стороны, более высокой стоимостью матрицы (поликарбоната), с другой - большей стоимостью наполнителя ввиду значительного увеличения его доли в композиционном материале.

Полученные данные о составе композитов для материалов теплообменных поверхностей свидетельствуют также о том, что в перечне разработанных композитов отсутствуют полимеры, наполненные микрочастицами меди. Данное обстоятельство связано с тем, что стоимость меди существенно превосходит стоимость других рассматриваемых наполнителей. Так, она превышает стоимость алюминия в 2,8 раза, а углеродных нанотрубок - 1,7 раза.

Характеризуя в целом материалы разработанного типоряда, следует также отметить, что они обладают высокой коррозионной стойкостью. Это является весьма важным при создании широко применяемых теплообменных аппаратов, которые эксплуатируются в условиях воздействия агрессивных сред. Традиционно в таких ситуациях в качестве материалов для теплообменных 


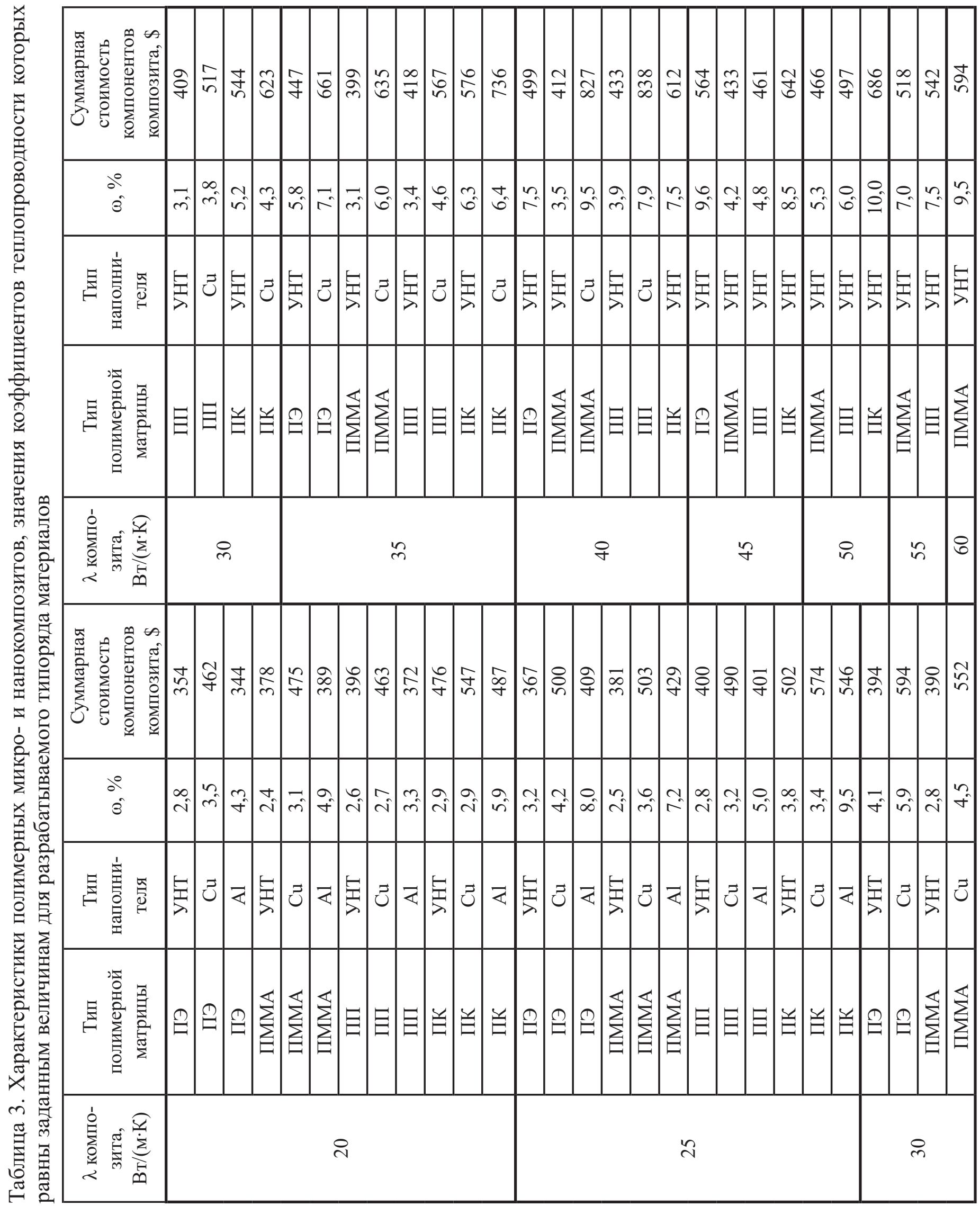


Таблица 4. Характеристики полимерных микро- и нанокомпозитов разработанного типоряда материалов для теплообменных поверхностей

\begin{tabular}{|c|c|c|c|c|c|c|}
\hline \multirow{2}{*}{$\begin{array}{c}\text { Обозначение } \\
\text { элементов } \\
\text { типоряда } \\
\text { материалов }\end{array}$} & \multirow[b]{2}{*}{$\begin{array}{c}\text { Тип } \\
\text { полимера }\end{array}$} & \multirow[b]{2}{*}{$\begin{array}{c}\text { Тип } \\
\text { наполнителя }\end{array}$} & \multirow[b]{2}{*}{$\omega, \%$} & \multicolumn{3}{|c|}{ Стоимость материалов, \$ } \\
\hline & & & & матрица & $\begin{array}{l}\text { напол- } \\
\text { нитель }\end{array}$ & $\begin{array}{c}\text { суммарная } \\
\text { стоимость } \\
\text { компонентов } \\
\text { композита }\end{array}$ \\
\hline A1 & $\Pi Э$ & $\mathrm{Al}$ & 4,3 & 257 & 87 & 344 \\
\hline $\mathrm{A} 2$ & ПЭ & УHT & 3,2 & 260 & 107 & 367 \\
\hline A3 & ПММА & УHT & 2,8 & 296 & 94 & 390 \\
\hline A4 & ПММА & УHT & 3,1 & 295 & 104 & 399 \\
\hline A5 & ПММА & УHT & 3,5 & 294 & 118 & 412 \\
\hline A6 & ПММА & УНT & 4,2 & 292 & 141 & 433 \\
\hline A7 & ПММА & УНT & 5,3 & 289 & 177 & 466 \\
\hline A8 & ПММА & УНT & 7,0 & 284 & 234 & 518 \\
\hline A9 & ПММА & УHT & 9,5 & 276 & 318 & 594 \\
\hline $\mathrm{B} 1$ & $\Pi \Pi$ & $\mathrm{Al}$ & 3,3 & 305 & 67 & 372 \\
\hline $\mathrm{B} 2$ & ПП & УHT & 2,8 & 306 & 94 & 400 \\
\hline B3 & ПП & УHT & 3,1 & 305 & 104 & 409 \\
\hline B4 & ПП & УHT & 3,4 & 304 & 114 & 418 \\
\hline B5 & ПП & УHT & 3,9 & 302 & 131 & 433 \\
\hline B6 & ПП & УНT & 4,8 & 300 & 161 & 461 \\
\hline B7 & $\Pi \Pi$ & УНT & 6,0 & 296 & 201 & 497 \\
\hline B8 & ПК & УНT & 7,5 & 291 & 251 & 542 \\
\hline $\mathrm{C} 1$ & ПК & УHT & 2,9 & 379 & 97 & 476 \\
\hline $\mathrm{C} 2$ & ПК & УHT & 3,8 & 375 & 127 & 502 \\
\hline $\mathrm{C} 3$ & ПК & УНT & 5,2 & 369 & 175 & 544 \\
\hline $\mathrm{C} 4$ & $\Pi К$ & УНT & 6,3 & 365 & 211 & 576 \\
\hline $\mathrm{C} 5$ & ПК & УНT & 7,5 & 361 & 251 & 612 \\
\hline C6 & ПК & УНT & 8,5 & 357 & 285 & 642 \\
\hline C7 & ПК & УНT & 10,0 & 351 & 335 & 686 \\
\hline
\end{tabular}

поверхностей применяется нержавеющая сталь. Сравнительная оценка показывает, что ее стоимость в 2 - 3 раза превышает стоимость разработанных полимерных микро- и нанокомпозитов.

\section{Выводы}

1. Для изготовления теплообменных поверхностей различного назначения разработан типоряд полимерных микро- и нанокомпозитов с коэффициентом теплопроводности, изменяю- щимся от 20 до $60 \mathrm{BT} /(\mathrm{M} \cdot \mathrm{K})$, и максимальной температурой эксплуатации, находящейся в пределах 390...470 К. Исследованы возможности использования в качестве элементов данного типоряда частично кристаллических (полиэтилена, полипропилена, поликарбоната) и аморфного (полиметилметакрылата) полимеров, наполненных углеродными нанотрубками или микрочастицами меди и алюминия.

2. Показано, что при повышении темпера- 
туры эксплуатации теплообменного аппарата имеет место тенденция к возрастанию доли наполнителя в соответствующих композиционных материалах. Установлено, что данное обстоятельство наряду с необходимостью применения более дорогостоящих полимерных матриц приводит к увеличению стоимости композитов.

3. Получены температурные зависимости удельной теплоемкости для разрабатываемых полимерных композитов и с их использованием найдены максимальные температуры эксплуатации данных композитов. Показано, что для всех рассматриваемых композиционных материалов на основе частично кристаллических полимеров эта температура не зависит от типа и массовой доли наполнителя и определяется по температуре плавления соответствующих полимеров. Установлено также, что для композитов на основе аморфных полимеров их максимальная температура эксплуатации является функцией типа наполнителя и его концентрации.

4. Выполнены экспериментальные исследования закономерностей изменения коэффициентов теплопроводности для рассматриваемых композиционных материалов. Определены значения первого и второго порогов перколяции, отвечающих образованию из частичек наполнителя соответственно непрерывного перколяционного кластера и перколяционной сетки. Для разработанных композитов на основе частично кристаллических полимеров установлено наличие корреляционной зависимости между степенью кристалличности композиционного материала и его теплопроводящими свойствами.

\section{ЛИТЕРАТУРА}

1. Cevallos J. G. Polymer Heat Exchangers History, Opportunities and Challenges / Juan Gabriel Cevallos, Arthur E. Bergles, Avram Bar Cohen, Peter Rodgers, Satyandra K. Gupta. - Heat Transfer Engineering. - 2012. - V. 33.- P. 1075- 1093.

2. Jesumathy $S$. Experimental study of enhanced heat transfer by addition of $\mathrm{CuO}$ nanoparticle / Stella Jesumathy, M. Udayakumar, S. Suresh. - Heat Mass
Transfer. - 2012. - V. 48. - P. $965-978$.

3. Wang $Q$. A review on application of carbonaceous materials and carbon matrix composites for heat exchangers and heat sinks / Q. Wang, X.H. Han, A. Sommers, Y. Park, C. T Joen, A. Jacobi. - International Journal of Refrigeration. - 2012. V. 38.- P. 7 - 26.

4. Yuchun Q. Experimental Investigation of a Novel Polymeric Heat Exchanger Using Modified Polypropylene Hollow Fibers / Yuchun Qin, Baoan Li, Shichang Wang. - Industrial \& Engineering Chemistry Research. - 2012. - V. 51.- P. $882-890$.

5. Elias M.M. Effect of nanoparticle shape on the heat transfer and thermodynamic performance of a shell and tube heat exchanger. / M.M. Elias, M. Miqdad, I.M. Mahbubul, R. Saidur, M. Kamalisarvestani, M.R. Sohel, Arif Hepbasli, N.A. Rahim, M.A. Amalina. - International Communications in Heat and Mass Transfer. - 2013. - V. 44.- P. 93 - 99.

6. Skokov K.P. Heat exchangers made of polymer - bonded La (Fe,Si) $)_{13}$.K.P. Skokov, D.Yu. Karpenkov, M.D. Kuz'm in, I.A. Radulov, T. Gottschall, B. Kaeswurm, M. Fries, O. Gutfleisch. Journal of Applied Physics. - 2014. - Vol. 115. - P. 17A941 - 17A943.

7. Dengshan Z. Grain and nanoparticle coarsening of an ultrafine structured $\mathrm{Cu}-5$ vol. 5 $\mathrm{Al}_{2} \mathrm{O}_{3}$ nanocomposite during isochronal annealing. / Dengshan Zhou, Deliang Zhang, Charlie Kong, Paul Munroe, Rob Torrens. - Journal of Alloys and Compounds. - 2015. - Vol. 642. - P. 83 - 91.

8. Берштейн В.A., Егоров В.М. Дифференциальная сканирующая калориметрия в физикохимии полимеров. - Л.: Химия, 1990. - 256 с.

9. Долинский A.A. Теплофизические свойства полимерных микро- и нанокомпозитов на основе поликарбоната / А. А. Долинский, Н. М. Фиалко, Р. В. Динжос, Р. А. Навродская // Промышленная теплотехника.- 2015. - №2. - С.12 - 19.

10. Долинский A. А. Влияние методов получения полимерных микро- и нанокомпозитов на их теплофизические свойства / А. А. Долинский, Н. М. Фиалко, Р. В. Динжос, Р. А. Навродская // Промышленная теплотехника.- 2015. - № 4. - С. 
$5-13$.

\section{THERMOPHYSICAL PROPERTIES OF THE HIGHLY HEAT-CONDUCTING POLYMERIC MICRO-AND NANOCOMPOSITES}

\section{Dolinskiy A.A. ${ }^{1}$, Fialko N.M. ${ }^{1}$, Dinzhos R.V. ${ }^{2}$, Navrodskaya R.A. ${ }^{1}$}

${ }^{1}$ Institute of Engineering Thermophysics, National Academy of Sciences of Ukraine, 2a, Zhelyabova str., Kyiv, 03680, Ukraine

${ }^{2}$ Nikolaev National University. named after V.A. Sukhomlinskiy, 24, Nikolska str., Mykolaev, 540030, Ukraine

Key words: polymer micro- and nanocomposites, heat transfer surfaces, thermophysical properties,

The results of studies to the develop of the type series of polymer micro- and nanocomposites with thermal conductivity varying from 20 to $60 \mathrm{~W} /(\mathrm{m} \cdot \mathrm{K})$, and the maximum operating temperature ranging $390 \ldots 470 \mathrm{~K}$ for the manufacture of heat transfer surfaces are presented. The possibility of use as elements this type series of partially crystalline and amorphous polymers (polyethylene, polypropylene, polycarbonate and polimetilmetakrylate) filled with carbon nanotubes or particles of copper and aluminum are considered. The experimental dependence from the temperature of specific heat of the developed composite materials and their conversion into data about values of the maximum operating temperature are gsven. Research materials to establish patterns of change in thermal conductivity of the developed materials by the mass fraction of fillers are presented.

References 10, fig. 3, tabl. 4.

1. Cevallos J. G. Polymer Heat Exchangers History, Opportunities and Challenges / Juan Gabriel Cevallos, Arthur E. Bergles, Avram Bar Cohen, Peter Rodgers, Satyandra K. Gupta. - Heat Transfer Engineering. - 2012. - V. 33.- P. 1075 - 1093.

2. Jesumathy $S$. Experimental study of enhanced heat transfer by addition of $\mathrm{CuO}$ nanoparticle / Stella Jesumathy, M. Udayakumar, S. Suresh // Heat Mass Transfer. - 2012. - V. 48. - P. 965 - 978.

3. Wang $Q$. A review on application of carbonaceous materials and carbon matrix composites for heat exchangers and heat sinks / Q. Wang, X.H. Han, A. Sommers, Y. Park, C. T Joen, A. Jacobi // International Journal of Refrigeration. - 2012. - V. 38.- P. $7-26$.

4. Yuchun Q. Experimental Investigation of a Novel Polymeric Heat Exchanger Using Modified Polypropylene Hollow Fibers / Yuchun Qin, Baoan Li, Shichang Wang // Industrial \& Engineering Chemistry Research. - 2012. - V. 51.- P. 882 - 890.

5. Elias M.M. Effect of nanoparticle shape on the heat transfer and thermodynamic performance of a shell and tube heat exchanger/M.M.Elias, M. Miqdad, I.M. Mahbubul, R. Saidur, M. Kamalisarvestani, M.R. Sohel, Arif Hepbasli, N.A. Rahim, M.A. Amalina // International Communications in Heat and Mass Transfer. - 2013. - V. 44.- P. 93 - 99.

6. Skokov K.P. Heat exchangers made of polymer- bonded $\mathrm{La}(\mathrm{Fe}, \mathrm{Si})_{13} /$ K.P. Skokov, D.Yu. Karpenkov, M.D. Kuz'min, I.A. Radulov, T. Gottschall, B. Kaeswurm, M. Fries, O. Gutfleisch // Journal of Applied Physics. - 2014. - Vol. 115. - P. 17A941 - 17A943.

7. Dengshan Z. Grain and nanoparticle coarsening of an ultrafine structured $\mathrm{Cu}-5$ vol.5 A12O3 nanocomposite during isochronal annealing / Dengshan Zhou, Deliang Zhang, Charlie Kong, Paul Munroe, Rob Torrens // Journal of Alloys and Compounds. - 2015. - Vol. 642. - P. 83 - 91.

8. Bernstein V.A. Differential Scanning Calorimetry in the physical chemistry of polymers / V.A. Bernstein, V.M. Egorov - L .: Chemistry, 1990. -256 p. (Rus)

9. Dolinskiy A.A. Thermophysical properties of polymer micro- and nanocomposites based on polycarbonate / A.A. Dolinskiy, N.M. Fialko, R.V. Dinzhos, R.A. Navrodskaya // Industrial heat engineering. - 2015. - №2. - P.12 -19. (Rus)

10. Dolinskiy A.A. Influence of methods of preparation of polymeric micro- and nanocomposites on their thermophysical properties / A.A. Dolinskiy, N.M. Fialko, R.V.Dinzhos, R.A. Navrodskaya // Industrial heat engineering. - 2015. - № 4. - P. 5 13.(Rus)

Получено 18.08.2015 Received 18.08.2015 